\title{
Effect of Screen Open Area on Active Screen Plasma Nitriding of Austenitic Stainless Steel
}

\author{
Akio NISHIMOTO, ${ }^{1 / *}$ Tatsuya MATSUKAWA ${ }^{2)}$ and Hiroaki NII) \\ 1) Department of Chemistry and Materials Engineering, Faculty of Chemistry, Materials and Bioengineering, Kansai University, \\ 2) Graduate Student, Graduate School of Science and Engineering, \\ Kansai University, 3-3-35 Yamate-cho, Suita, Osaka, 564-8680 Japan. \\ 3) Formerly Graduate Student, Graduate School of \\ Science and Engineering, Kansai University. Now at Kobe Steel, Ltd., 1-5-5 Takatsukadai, Nishi-ku, Kobe, Hyogo, 651-2271 Japan.
}

(Received on October 23, 2013; accepted on November 21, 2013)

\begin{abstract}
Austenitic stainless steel SUS 316 L was nitrided by active screen plasma nitriding (ASPN) using screens with various open areas to investigate the effect of the screen's open area ratio on the nitriding response. The sample was placed on the sample stage in a floating potential and isolated from the cathodic screen and anode. The screen, which was SUS 316L expanded metal mesh with $38 \%, 48 \%$, or $63 \%$ open area ratio, was mounted on the cathodic stage around the sample stage. Nitriding was performed in a nitrogen-hydrogen atmosphere with $25 \% \mathrm{~N}_{2}+75 \% \mathrm{H}_{2}$ for $18 \mathrm{ks}$ at $693 \mathrm{~K}$ under $600 \mathrm{~Pa}$ by the ASPN process. After nitriding, the nitrided microstructure was examined using a scanning electron microscope and an electron probe microanalyzer. The phase structures on the nitrided surface were determined by X-ray diffraction. In addition, the surface hardness and cross section of the nitrided samples were measured by the use of a Vickers microhardness tester. The thickness of the nitrided layer of the S-phase decreased with increasing open area ratio of the screen.
\end{abstract}

KEY WORDS: surface engineering; active screen plasma nitriding; cathodic cage; S-phase; stainless steel; open area ratio.

\section{Introduction}

Nitriding is a surface hardening process that is widely used to improve the tribological properties and wear resistance of steel and titanium alloys. Compared with conventional nitriding processes such as gas nitriding and salt bath nitriding, the glow-discharge plasma nitriding process offers the following advantages: no pollution, high nitrogen potential, short treatment time, clean environment, and low energy consumption. ${ }^{1-8)}$ Furthermore, in the plasma nitriding process, the components to be treated are subjected to a high cathodic potential, which results in the production of plasma directly on their surfaces. As a result, an "edge effect" occurs, even though the components are well heated, as the electric field around the corners and edges of the components is distorted. This results in the nonuniformity of surface properties such as hardness and thickness of the surface layer. ${ }^{9)}$

Recently, considerable interest has been paid to alternative nitriding processes such as active screen plasma nitriding (ASPN), through-cage plasma nitriding, and cathodic-cage plasma nitriding. ${ }^{10-20)}$ These processes offer the advantage of completely eliminating the edge effect associated with conventional plasma nitriding processes, as the plasma is produced on the screen and not directly on the samples. ${ }^{10-13)}$

* Corresponding author: E-mail: akionisi@kansai-u.ac.jp DOI: http://dx.doi.org/10.2355/isijinternational.54.916
These processes can be used to treat polymers that are nonconductive materials. ${ }^{21-24)}$ Several researchers have reported the effects of nitriding parameters such as the distance between screen and sample, screen size, gas pressure, gas composition, sample geometry, and bias voltage on ASPN properties. ${ }^{25-38)}$ However, little information has been reported on the effect of the screen's open area ratio on ASPN properties. In this study, ASPN has been performed on austenitic stainless steel by using three types of screens with various open area ratios to investigate the effect of the screen's open area on the nitriding properties.

\section{Materials and Methods}

The sample material analyzed in this study was austenitic stainless steel SUS 316L with a chemical composition (mass $\%$ ) of $0.013 \% \mathrm{C}, 0.30 \% \mathrm{Si}, 1.67 \% \mathrm{Mn}, 0.034 \% \mathrm{P}$, $0.011 \% \mathrm{~S}, 16.89 \% \mathrm{Cr}, 12.26 \% \mathrm{Ni}, 2.00 \% \mathrm{Mo}$, and the balance being Fe. A sample disk was $20 \mathrm{~mm}$ in diameter and $5 \mathrm{~mm}$ in thickness. Prior to nitriding, the sample surface was mechanically ground with 150-1200-grit SiC, finely polished with $0.05 \mu \mathrm{m}$ alumina suspension, ultrasonically degreased in acetone, and dried in air. The preconditioned sample was then placed in a nitriding furnace for further ASPN treatment.

In this study, ASPN experiments were conducted with a DC plasma-nitriding unit (NDK, Inc., Japan, JIN-1S). A ceramic crucible was placed on the cathodic stage to con- 


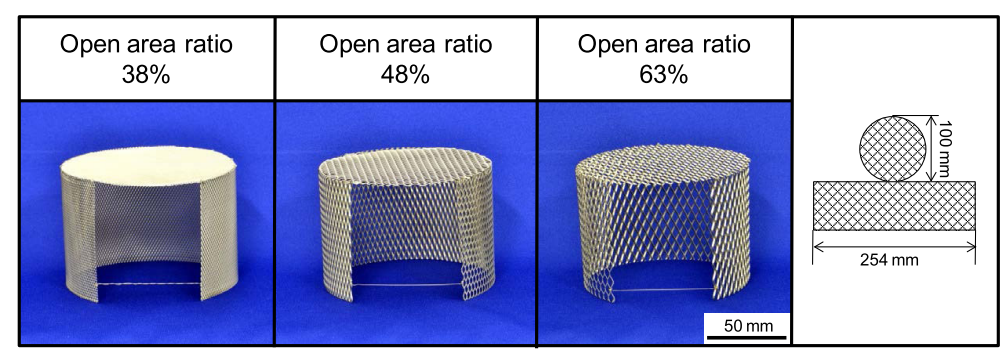

Fig. 1. Appearance, size, and open area ratio of SUS 316L steel screen. (Online version in color.)

struct an isolated sample stage. The sample was placed on the sample stage in a floating potential and isolated from the cathodic screen and anode. The screen material used in this study was SUS 316L of expanded metal mesh, formed into a cylinder of $100 \mathrm{~mm}$ diameter and $70 \mathrm{~mm}$ height. This screen was mounted on the cathodic stage around the sample stage. Three types of screens with open areas of $38 \%$, $48 \%$, and 63\% were used, as shown in Fig. 1. The distance between the screen and sample was $10 \mathrm{~mm}$. The screen was thoroughly degreased ultrasonically in acetone.

Nitriding was performed in a nitrogen-hydrogen atmosphere composed of $25 \% \mathrm{~N}_{2}+75 \% \mathrm{H}_{2}$ for $18 \mathrm{ks}$ at $693 \mathrm{~K}$ under $600 \mathrm{~Pa}$. After placing the sample on the sample stage, the chamber was evacuated to a pressure of approximately $6 \mathrm{~Pa}$. Subsequently, nitrogen and hydrogen were introduced into the chamber, together with an applied DC bias voltage. After nitriding, the DC supply was switched off, and the sample was cooled to room temperature. The nitriding temperature was monitored with a radiation thermometer positioned at the sample.

The surface roughness of the untreated and nitrided samples was determined by a stylus profilometer (Mitutoyo, Japan, Surftest-402 and Surftest Analyzer 178 Series). The phase structure on the nitrided surface was determined by $\theta$ $2 \theta$ X-ray diffraction (XRD; RIGAKU, Japan, RINT$2550 \mathrm{~V})$. The entire area of the top surface of nitrided samples was analyzed by XRD. The nitrided microstructure and compositional analysis of nitrogen were examined with a scanning electron microscope (SEM; JEOL, Japan, JSM$6060 \mathrm{LV}$ ) and an electron probe microanalyzer (EPMA; JEOL, Japan, JXA-8800). For this, cross sections of each sample were first cut using a low-speed saw, then polished, and chemically etched. In addition, the surface hardness and cross sections of the nitrided samples were measured with a Vickers microhardness tester (Matsuzawa, Japan, MXT50) under a $0.1-\mathrm{N}$ load. Five indentations were made on each sample; of the five values, the maximum and minimum were discarded, and the average of the remaining three was taken as the hardness value.

\section{Results and Discussion}

The external appearance of the nitrided samples was visually examined, as shown in Fig. 2. The appearance of all samples seemed the same irrespective of the screen's open area ratio. All the samples treated by the ASPN process were uniform, without the presence of the edge effect. The edge effect was avoided, because the sample's isolation prevented the formation of glow discharge on the sample sur-

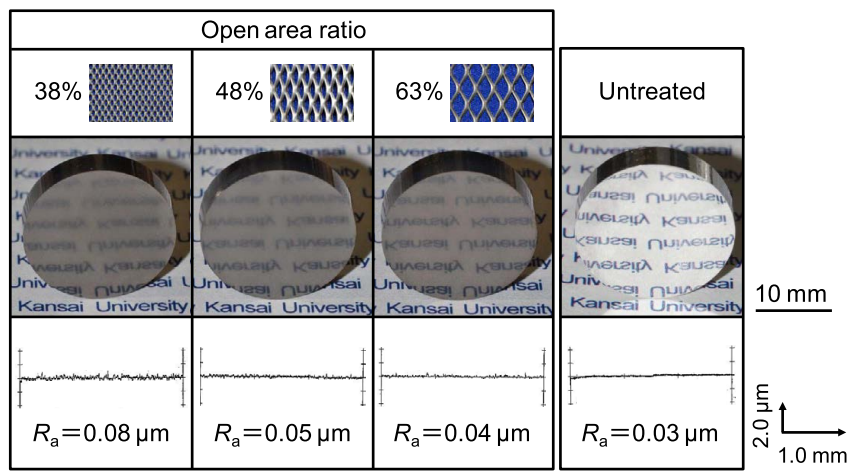

Fig. 2. External appearance and roughness of the untreated and treated SUS 316L steel sample surfaces for $18 \mathrm{ks}$ at $693 \mathrm{~K}$ in the ASPN process. (Online version in color.)

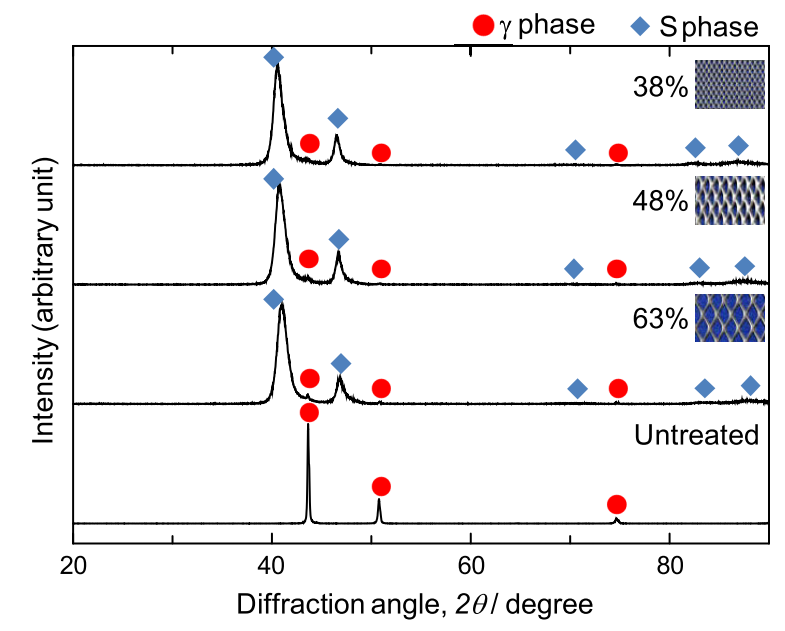

Fig. 3. XRD patterns of the samples untreated and treated for $18 \mathrm{ks}$ at $693 \mathrm{~K}$ in the ASPN process. (Online version in color.)

face. ${ }^{10-13)}$ The surface roughness of nitrided and untreated samples is also shown in Fig. 2. The roughness of the untreated sample after polishing was determined to be $0.03 \mu \mathrm{m}$. The roughness of the nitrided samples was higher than that of the untreated sample; however, the roughness values of the nitrided samples were still considered low. In addition, the surface roughness of the nitrided samples tended to increase with decreasing open area ratio of the screen. It is thought that a compound layer resulting from the decomposition of $\mathrm{Fe}_{\mathrm{x}} \mathrm{N}$ on the sample surface grew as the open area ratio of the screen decreased.

Figure 3 shows the XRD patterns of the untreated sample and samples treated by the ASPN process. The XRD patterns indicate that $\gamma$-austenite and the S-phase (expanded 
austenite), which is considered to be a supersaturated solid solution of nitrogen in the austenitic phase, ${ }^{39-43)}$ were identified on the surfaces of the nitrided samples. For ASPNtreated samples, the S-phase formed on each sample had the same intensity irrespective of the open area ratio of the screen.

The microstructures of the cross sections of the samples treated by the ASPN process are shown in Fig. 4. An Sphase layer of less than $5 \mu \mathrm{m}$ in thickness, which was slightly corroded by oxalic acid, was observed on the sample surfaces. Figure 5 shows the effect of the screen's open area ratio on the nitrided layer thickness. The thickness of the nitrided S-phase layer decreased as the open area ratio increased; the nitriding temperature of all samples was essentially the same. Figure 6 shows the EPMA line analysis curve of nitrogen. This result clearly shows the enrichment of nitrogen in the surface region. The nitrogen profile obtained suggests a surface region, in which the nitrogen intensity decreased gradually, is the S-phase layer. In each sample the penetration depth of nitrogen into the sample substrate is in good agreement with the thickness of the Sphase layer, as shown in Figs. 4 and 5; that is the penetration depth of nitrogen increased with decreasing open area ratio of the screen. These results indicate that the amount of active species available for nitriding increases as the open area ratio of the screen decreases. As a result, the nitrided layer of greatest thickness was obtained at the open area ratio of $38 \%$.

Figure 7 shows the cross-sectional hardness distribution of the samples treated by the ASPN process. The hardness

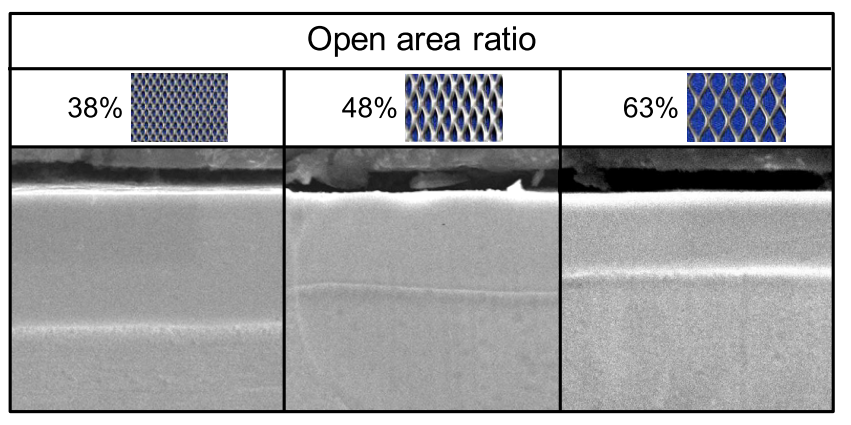

$5 \mu \mathrm{m}$

Fig. 4. Microstructure of the cross section of samples treated for $18 \mathrm{ks}$ at $693 \mathrm{~K}$ in the ASPN process. (Online version in color.)

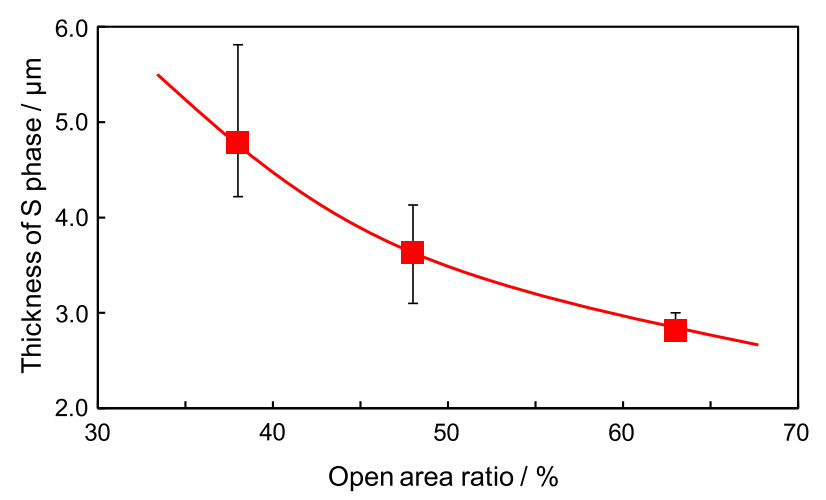

Fig. 5. Effect of the open area ratio of the screen on the thickness of the S-phase layer after ASPN. (Online version in color.) decreased considerably toward the core of the substrate in each condition. In addition, the hardening effect on the sample nitrided with the $38 \%$ open screen was greater than that from use of other screens. Moreover, the surface hardness of the sample nitrided with the $38 \%$ open screen was also greater than that from the use of other screens. Surface hardness was dependent on the screen's open area ratio, because that ratio affected the thickness of the S-phase layer on the surface, as shown in Figs. 4 and 5.

Figure 8 shows a schematic illustration of the mechanism of nitrogen mass transfer in ASPN. At a lower open area ratio, the number of sputtered particles on the active screen increased because of the large area of screen material. Therefore, the deposition of nitrides from the screen

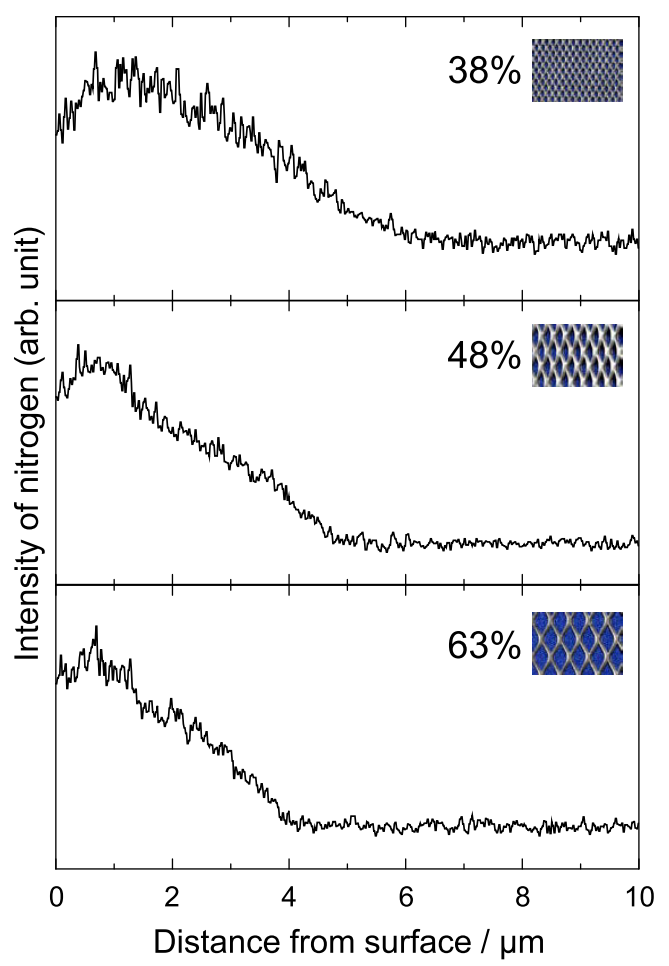

Fig. 6. EPMA line analysis of nitrogen of the samples treated for $18 \mathrm{ks}$ at $693 \mathrm{~K}$ in the ASPN process. (Online version in color.)

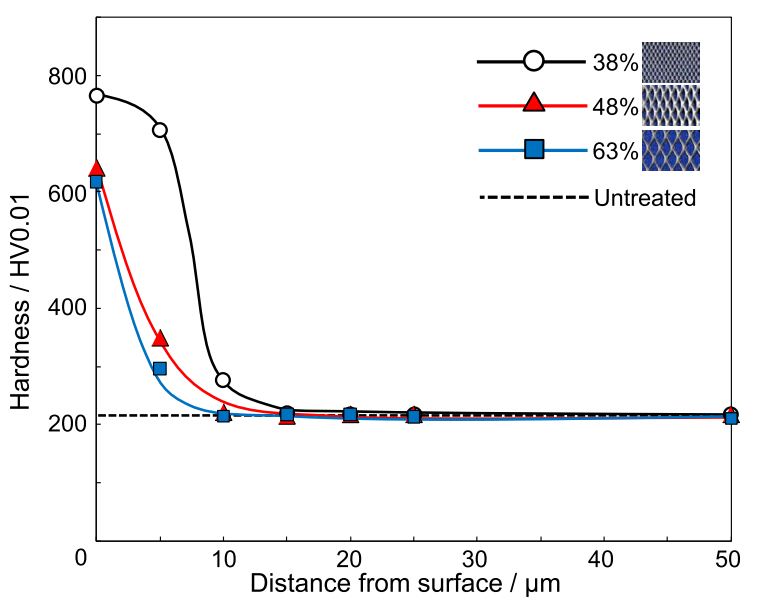

Fig. 7. Cross-sectional hardness distribution of the SUS $316 \mathrm{~L}$ samples treated for $18 \mathrm{ks}$ at $693 \mathrm{~K}$ in the ASPN process. (Online version in color.) 


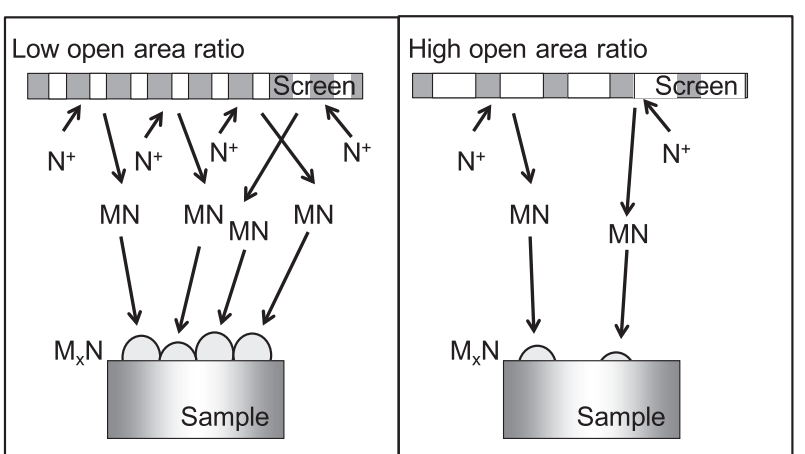

Fig. 8. Schematic illustration of the mechanism of nitrogen mass transfer in the ASPN process

increased as the screen's open area ratio decreased. As a result, the nitrided layer with the greatest thickness and hardness was obtained at the open area ratio of $38 \%$. From this study on the effect of open area ratio of the screen on ASPN, we concluded that the amount of material transferred from the screen mesh onto the nitrided specimens played a significant role in the hardening effect. Several researchers have proposed a model of "sputtering and deposition" during ASPN. ${ }^{11,44-46)}$ In this model, nitrogen ions sputter the screen, the sputtered materials form nitrides with nitrogen in the plasma, and nitrides deposit on the sample's surface. It is thought that this model can be adapted to this study.

\section{Conclusions}

Austenitic stainless steel SUS 316L was nitrided by ASPN using screens with various open areas to investigate the effect of the screen's open area ratio on nitriding response. All the samples treated by the ASPN process were uniform, without the presence of edge effect. The XRD pattern and cross-sectional morphology of the nitrided samples indicated the formation of the S-phase on the samples' surfaces. The thickness of the nitrided layer of the S-phase increased with decreasing open area ratio of the screen.

\section{Acknowledgement}

The authors thank Kansai Tekko Co., Ltd., Japan for supplying screen materials of expanded metal mesh.

\section{REFERENCES}

1) Y. Sun and T. Bell: Mater. Sci. Eng. A, 140 (1991), 419.

2) M. Samandi, B. A. Shedden, D. I. Smith, G. A. Collins, R. Hutchings and J. Tendys: Surf. Coat. Technol., 59 (1993), 261.

3) A. Nishimoto and K. Akamatsu: Plasma Process. Polym., 6 (2009), s306.

4) H. Dong: Int. Mater. Rev., 55 (2010), 65.

5) M. Egawa, N. Ueda, K. Nakata, M. Tsujikawa and M. Tanaka: Surf. Coat. Technol., 205 (2010), S246.

6) W. Li, X. Li and H. Dong: Acta Mater., 59 (2011), 5765.

7) S. Adachi and N. Ueda: Thin Solid Films, 523 (2012), 11
8) H. Nagamatsu, R. Ichiki, Y. Yasumatsu, T. Inoue, M. Yoshida, S. Akamine and S. Kanazawa: Surf. Coat. Technol., 225 (2013), 26.

9) C. Alves, Jr., E. F. da Silva and A. E. Martinelli: Surf. Coat. Technol., 139 (2001), 1.

10) C. X. Li, T. Bell and H. Dong: Surf. Eng., 18 (2002), 174.

11) C. Zhao, C. X. Li, H. Dong and T. Bell: Surf. Coat. Technol., 201 (2006), 2320.

12) C. Alves, Jr., F. O. de Araujo, K. J. B. Ribeiro, J. A. P. da Costa, R. R. M. Sousa and R. S. de Sousa: Surf. Coat. Technol., 201 (2006), 2450.

13) C. X. Li: Surf. Eng., 26 (2010), 135.

14) A. Nishimoto, T. E. Bell and T. Bell: Surf. Eng., 26 (2010), 74.

15) Y. Li, L. Wang, D. Zhang and L. Shen: J. Alloys Compds., 497 (2010), 285

16) Y. Dong, X. Li, R. Sammons and H. Dong: J. Biomed. Mater. Res. Part B: Appl. Biomater., 93B (2010), 185.

17) K. Nagatsuka, A. Nishimoto and K. Akamatsu: Surf. Coat. Technol., 205 (2010), S295.

18) S. Corujeira Gallo and H. Dong: Scr. Mater., 67 (2012), 89.

19) I. Burlacov, K. Börner, H. J. Spies, H. Biermann, D. Lopatik, H. Zimmermann and J. Röpcke: Surf. Coat. Technol., 206 (2012), 3955.

20) A. Nishimoto, H. Nii, R. Narita and K. Akamatsu: Surf. Coat. Technol., 228 (2013), S558.

21) A. P. Kauling, G. V. Soares, C. A. Figueroa, R. V. B. de Oliveira, I. J. R. Baumvol, C. Giacomelli and L. Miotti: Mater. Sci. Eng. C, 29 (2009), 363.

22) G. Kaklamani, N. Mehrban, J. Chen, J. Bowen, H. Dong, L. Grover and A. Stamboulis: Biomed. Mater., 5 (2010), 054102.

23) X. Fu, R. L. Sammons, I. Bertoti, M. J. Jenkins and H. Dong: $J$. Biomed. Mater. Res. Part B: Appl. Biomater., 100B (2012), 314.

24) G. Kaklamani, J. Bowen, N. Mehrban, H. Dong, L. M. Grover and A. Stamboulis: Appl. Surf. Sci., 273 (2013), 787.

25) Sh. Ahangarani, F. Mahboubi and A. R. Sabour: Vacuum, 80 (2006), 1032.

26) P. Hubbard, S. J. Dowey, E. D. Doyle and D. G. McCulloch: Surf. Eng., 22 (2006), 243.

27 R. R. M. de Sousa, F. O. de Araujo, K. J. B. Ribeiro, M. W. D. Mendes, J. A. P. da Costa and C. Alves, Jr.: Mater. Sci. Eng. A, 465 (2007), 223.

28) A. Nishimoto, A. Tokuda and K. Akamatsu: Mater. Trans., 50 (2009), 1169.

29) S. Corujeira Gallo and H. Dong: Surf. Coat. Technol., 203 (2009), 3669.

30) R. R. M. de Sousa, F. O. de Araujo, J. A. P. da Costa, T. Dumelow, R. S. de Oliveira and C. Alves, Jr.: Vacuum, 83 (2009), 1402.

31) Sh. Ahangarani, A. R. Sabour, F. Mahboubi and T. Shahrabi: J. Alloys Compds., 484 (2009), 222.

32) A. Nishimoto, K. Nagatsuka, R. Narita, H. Nii and K. Akamatsu: Surf. Coat. Technol., 205 (2010), S365.

33) P. Hubbard, J. G. Partridge, E. D. Doyle, D. G. McCulloch, M. B. Taylor and S. J. Dowey: Surf. Coat. Technol., 204 (2010), 1145.

34) P. Hubbard, S. J. Dowey, J. G. Partridge, E. D. Doyle and D. G. McCulloch: Surf. Coat. Technol., 204 (2010), 1151.

35) A. Nishimoto, K. Nagatsuka, R. Narita, H. Nii and K. Akamatsu: $J$. ASTM Int., 8 (2011), JAI103286.

36) Z. Soltani Asadi and F. Mahboubi: Mater. Design, 344 (2012), 516.

37) R. R. M. de Sousa, F. O. de Araujo, L. C. Gontijo, J. A. P. da Costa and C. Alves, Jr.: Vacuum, 86 (2012), 2048.

38) N. D. Daudt, J. C. P. Barbosa, M. D. C. Macedo, M. B. Pereira and C. Alves, Jr.: Mater. Res., 16 (2013), 766.

39) Z. L. Zhang and T. Bell: Surf. Eng., 1 (1985), 131.

40) K. Ichii, K. Fujimura and T. Takase: Technol. Rep. Kansai Univ., 27 (1986), 135.

41) T. Bell: Key Eng. Mater., 373-374 (2008), 289.

42) J. Buhagiar, X. Li and H. Dong: Surf. Coat. Technol., 204 (2009), 330 .

43) T. L. Christiansen, T. S. Hummelshoj and M. A. J. Somers: Surf. Eng., 26 (2010), 242.

44) S. C. Gallo and H. Dong: Vacuum, 84 (2010), 321.

45) H. Nii and A. Nishimoto: J. Phys. Conf. Ser., 379 (2012), 012052.

46) A. Saeed, A. W. Khan, F. Jan, M. Abrar, M. Khalid and M. Aakaullah: Appl. Surf. Sci., 273 (2013), 173. 